„Przekłady Literatur Słowiańskich”. T. 11, cz. 1, s. 1-18

ISSN 2353-9763 (wersja elektroniczna)

DOI https://doi.org/10.31261/PLS.2021.11.01.17

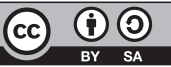

\title{
Przekład modernistyczny w kulturach słowiańskich Kilka uwag wstępnych
}

\section{Modernist Translation in Slavic Cultures A Few Introductory Remarks}

\section{Tamara Brzostowska-Tereszkiewicz}

iD https://orcid.org/0000-0001-5225-3307

POLISH ACADEMY OF SCIENCES

tamara.brzostowska@ibl.waw.pl

Data zgłoszenia: 22.10.2021 r. ｜Ｄata akceptacji: 15.11.2021 r.

\begin{abstract}
The article discusses the growing interest in Central and Eastern European literary modernisms in the context of the transnational turn, the translational turn and the archival turn recently diagnosed in the New Modernist Studies. The aims of the investigations are twofold: (1) to draw attention to the specificity of Slavic cultures of artistic translation and their ability to refocus and rebalance Western Eurocentric research on literary modernism, and (2) to introduce a new series of studies of the transnational interconnections between Slavic modernisms.
\end{abstract}

KEYWORDS | Slavic modernism, comparative modernism studies, transnational turn, modernist translation 


\section{Horyzonty badań nad nowoczesnością}

W nowych studiach modernistycznych ostatniego dwudziestolecia refleksję nad ponadregionalną, ogólnoformacyjną specyfiką europejskiego modernizmu literackiego coraz wyraźniej przeciwważy nurt dociekań komparatystycznych eksponujących zagadnienia geopolitycznej odrębności, prądowych i terminologicznych antynomii oraz historyczno-kulturowej swoistości modernizmów regionalnych ${ }^{1}$. Zwrot transnarodowy w historiografii modernistycznej, zdiagnozowany przez Douglasa Mao i Rebeccę L. Walkowitz, nie tylko pozwolił włączyć w obszar badawczej uwagi heterogeniczne tradycje kulturowe, lecz także umożliwił rewizję periodyzacji dziejów, historycznej genealogii i wzajemnych zależności poszczególnych modernizmów. „Dziś coraz bardziej badaczy interesują modernizmy lokalne"² - wyjaśnia Ewa Paczoska, wiążąc rozwój obserwowanych tendencji ze zwrotem topograficznym i nowym regionalizmem we współczesnych badaniach literackich. To przesunięcie zainteresowań badawczych humanistyki z centrum na peryferie pozwoliło uwidocznić napięcia między głównymi ośrodkami promieniowania modernizmu, utożsamianymi z wielkomiejskimi doświadczeniami Europy Zachodniej, a wielonarodowościowymi i różnojęzycznymi prowincjami ${ }^{3}$.

Myślenie o formacji modernistycznej w perspektywie wielorako połączonych geomodernizmów powoduje uniezwyklenie samej kategorii modernizmu. Rzeczniczki lokalizacyjnego podejścia do modernizmu, Laura Doyle i Laura Winkiel, podkreślają, że koncentracja na roli poszczególnych regionów w kulturowych, politycznych i społecznych dyskursach globalnej nowoczesności pozwala ujawniać modernistyczne innowacje w tekstach uznawanych dotąd

1 Zob. D. Mao, R.L. Walkowitz, 2014: Nowe studia modernistyczne. A. i M. Kęsiakowie, tłum. „Poznańskie Studia Polonistyczne. Seria Literacka”, nr 24, s. 97-115; S.S. Friedman, 2007: Cultural Parataxis and Transnational Landscapes of Reading. Toward a Locational Modernist Studies. W: A. Eysteinsson, V. Liska, eds.: Modernism. Vol. 1. Amsterdam-Philadelphia, Johns Benjamins Publishing Company, s. 35-52; S. Latham, G. Rogers, eds., 2021: The New Modernist Studies Reader: An Anthology of Essential Criticism. [S.1.] Bloomsbury Publishing.

2 E. Paczoska, 2017: Słowo wstępne. W: E. Paczoska, I. Poniatowska, M. Chmurski, red.: Problemy literatury $i$ kultury modernizmu w Europie Środkowo-Wschodniej (18671918). T. 1: Teksty doświadczenia. Warszawa, Wydawnictwa Uniwersytetu Warszawskiego, s. 7.

3 Zob. I. Poniatowska, 2017: Słowo wstępne. W: E. Paczoska, I. Poniatowska, M. Chmurski, red.: Problemy literatury i kultury modernizmu w Europie Środkowo-Wschodniej (1867-1918). T. 3: Wspólnota pytań. Antologia. Warszawa, Wydawnictwa Uniwersytetu Warszawskiego, s. 7-8. 
za marginesowe, peryferyjne, drugoplanowe. Wydobywa też nieoczekiwane korelacje między tymi tekstami a innymi, uchodzącymi za bardziej tradycyjne, konwencjonalne lub, przeciwnie, eksperymentalne, postmodernistyczne ${ }^{4}$. Rozszerzenie badań nad geografiami modernizmu ${ }^{5} \mathrm{z}$ jednej strony oraz uhistorycznianie literackiej nowoczesności z drugiej — powodują istotne przetasowania wewnątrz europejskiego dziedzictwa kulturowego. Odsłaniają nieznane dotąd rejony modernistycznej konstelacji oraz niezbywalną obecność modernizmu w dyskursach artystycznych XXI wieku.

Wśród istotnych następstw transnarodowych i zarazem regionalistycznych tendencji w najnowszych badaniach porównawczych nad modernizmem szczególnie istotne dla prezentowanych tu rozważań są dwa, a mianowicie: (1) znaczne poszerzenie pola badań o historię i poetykę przekładu artystycznego oraz (2) dynamiczny rozwój studiów nad środkowo- i wschodnioeuropejskimi wariantami europejskiego modernizmu ${ }^{6}$.

Decydujące przesunięcie uwagi na przekład artystyczny jako kluczowy czynnik warunkujący międzykulturową ekspansję, transmisję i transformację nowoczesnych stylów, poetyk, języków artystycznych pozwala mówić o zwrocie translacyjnym w studiach porównawczych nad modernizmami ${ }^{7}$. Przekład jako jeden z dyskursów nowoczesnej literatury okazuje się nieodłącznym składnikiem modernistycznego programu kulturowej odnowy i artystycznej innowacji, swoistym laboratorium ekspresywnych możliwości języka poetyckiego oraz istotnym środkiem rozszerzania jego granic w poszczególnych literaturach narodowych. W ostatnich latach badaniom nad nowoczesnym przekładem literackim towarzyszą intensywne eksploracje archiwów regionalnych modernizmów literackich. Zwrot archiwalny w nowych studiach modernistycznych ${ }^{8}$,

4 Zob. L. Doyle, L. Winkiel, 2005: Introduction: The Global Horizons of Modernism. W: L. Doyle, L. Winkiel, eds.: Geomodernism. Race, Modernism, Modernity. Bloomington, Indiana University Press, s. 3.

5 Zob. P. Brooker, A. Thacker, eds., 2005: Geographies of Modernism: Literatures, Cultures, Spaces. London-New York, Routledge.

6 Zob. m.in. trzytomowe wydanie Problemy literatury i kultury modernizmu w Europie Środkowo-Wschodniej (1867-1918) (t. 1: Teksty doświadczenia, 2017; t. 2: Doświadczenia tekstu, 2017; t. 3: Wspólnota pytań. Antologia, 2017); M. Chmurski, 2013: Modernizm(y) Europy Środkowej. Rekonesans. „Przegląd Filozoficzno-Literacki”, nr $1-2$, s. $1-17$.

7 T. Brzostowska-Tereszkiewicz, 2016: The Translational Turn in Modernism Studies. W: A. Adamowicz-Pośpiech, M. Mamet-Michalkiewicz, eds.: Translation in Culture. Katowice, Wydawnictwo Uniwersytetu Śląskiego, s. 13-38; S.G. Yao, 2013: Translation Studies and Modernism. W: J.-M. Rabaté, ed.: A Handbook of Modernism Studies. West Sussex, Wiley-Blackwell, s. 209-223.

8 Zob. N. Milthorpe, 2019: Archives, Authority, Aura: Modernism's Archival Turn. „Papers on Language and Literature", nr 1, s. 3-15. Tendencje archiwistyczne uwyraźnia 
jak wyjaśnia James A. Knapp, umożliwia istotną „korektę ahistorycznego teoretyzowania"9 na gruncie badań empirycznych. Przeniesienie znacznej części debaty literaturoznawczej do archiwów sprzyja nowym projektom historii literatury tłumaczonej $^{10}$, a także monograficznym opracowaniom dorobku twórczego tłumaczy, przede wszystkim zaś badaniom nad biografiami translatorskimi i egodokumentami przekładowców ${ }^{11}$. Trendy te ściśle splatają się z nurtem badań nad tłumaczem ${ }^{12}$, które wyostrzają wrażliwość teoretyków i krytyków przekładu na zagadnienia podmiotowej percepcji, indywidualnego artyzmu i społeczno-kulturowej aktywności tłumaczy w szeroko rozumianym polu translatorskim.

Symptomatycznym, regionalnym przykładem wzajemnie sprzężonych tendencji archiwistycznych i „tłumaczoznawczych” w badaniach nad modernistycznym przekładem literackim jest studium Beaty Kalęby Wyrwa w świecie. Przekład literacki w sowieckiej Litwie - casus Tomasa Venclovy i rówieśników (2019) ${ }^{13}$. Autorka prezentuje w nim dokumenty translatorskie jako sytuacyjnie uwarunkowane wypowiedzi kulturowe powstałe w określonych okolicznościach (w analizowanym przypadku: wileńskie, kowieńskie, moskiewskie i leningradzkie życie artystyczne i akademickie w warunkach państwa totalitarnego), w konkretnym celu (przekład jako enklawa twórczej wolności), przez kogoś zapisane, odczytywane

seria wydawnicza Historicizing Modernism pod redakcją M. Feldmana i E. Tonninga, szczególnie najnowszy tom: Historicizing Modernists. Approaches to "Archivalism” opracowany przez redaktorów serii oraz A. Svendsen (2021).

9 J.A. Knapp, 2003: „Ocular Proof”: Archival Revelations and Aesthetic Response. „Poetics Today", nr 4, s. 695; cyt. za: F. Fordham, 2010: The Modernist Archive. W: P. Brooker et al., eds.: The Oxford Handbook of Modernisms. Oxford, Oxford University Press, s. 47.

10 Na przykład A. Pym, 2009: Humanizing Translation History. „Hermes”, nr 22, s. $23-$ 48; I. Tyšš, E. Gromová, 2020: Taking Matters into our Own Hands: Humanizing Slovak Translation History. „Porównania”, nr 1, s. 157-176.

11 Zob. np. J. Kita-Huber, R. Makarska, red., 2020: Wyjść ttumaczowi naprzeciw. Miejsce tłumacza w najnowszych badaniach translatologicznych. Kraków, Universitas; a także artykuły zgromadzone w piśmie „Porównania” 2020, nr 1: Czynnik ludzki w przekładzie literackim. Teorie, historie, praktyki.

12 Zob. A. Chesterman, 2009: The Name and Nature of Translator Studies. „Hermes”, nr 42, s. 13-22.

13 Studium opiera się na materiałach archiwalnych z zasobów Archiwów Tomasa Venclovy i ojca poety - Antanasa Venclovy w Instytucie Literatury Litewskiej i Folkloru w Wilnie; Archiwów Tomasa Venclovy i Czesława Miłosza w Beinecke Library w Yale (USA); prywatnych archiwów Virgilijusa Čepaitisa, Wiktora Woroszylskiego oraz Archiwum Jana Błońskiego w Bibliotece Jagiellońskiej. Prezentację unikatowych źródeł pisanych uzupełnia historia mówiona - relacje ustne rówieśników litewskiego poety oraz wyimki z ich prywatnej korespondencji z autorką studium. 
i komentowane ${ }^{14}$. Przedemigracyjna twórczość translatorska Venclovy jest dla literaturoznawczyni reprezentatywnym świadectwem literacko-intelektualnej samowiedzy litewskiego modernizmu. Wiążąc elementy różnorodnych postaw ideowych, etycznych i artystycznych dochodzących do głosu w środowiskach inteligenckich, staje się punktem ogniskowym, w którym zbiegają się rozmaite dyskursy kulturowe sowieckiej Litwy. W tym tomie „Przekładów Literatur Słowiańskich” znaleziska z archiwów modernistycznego przekładu zostały zaprezentowane w szkicu historycznym Beaty Kalęby o Dtugiej drodze do litewskiego przekładu „Traktatu poetyckiego” Czesława Miłosza, dokumentującym „ludzki i literacki dialog"15 polskiego poety z Tomasem Venclovą. Wyrazista deklaracja metodologiczna złożona przez polską lituanistkę trafia w sedno badań nad literackim modernizmem skoncentrowanych na aktywności tłumaczy:

jestem zwolenniczką takiego rozumienia relacji pomiędzy tekstem wyjściowym a jego przekładem na inny język oraz między autorem tekstu tłumaczonego a autorem przekładu, które nakazuje dokonywać odczytania utworu literackiego, który jest tłumaczeniem z innego języka, w pierwszym rzędzie mając na uwadze kontekst biografii autora utworu określanego jako przekład oraz literatury i sytuacji pozaliterackiej w kulturze języka przekładu ${ }^{16}$.

Badania transnarodowych powiązań literackich w kulturach polskiej, czeskiej, słowackiej, węgierskiej, chorwackiej, serbskiej, ukraińskiej czy litewskiej, wspierane przez poszukiwania archiwalne, prowadzą do stopniowej reorientacji i zrównoważenia zachodnioeuropejskich studiów modernistycznych z punktu widzenia Europy Środkowej i Wschodniej ${ }^{17}$. Tę znaczącą zmianę perspektywy badawczej odnotowuje historyk wiedeńskiej moderny - Mateusz Chmurski: „Często marginalizowane w badaniach zachodnich doświadczenia artystyczne Europy Środkowo-Wschodniej dziś traktuje się jako zasadnicze dla głównego nurtu historii nowoczesności”18. Jest przy tym rzeczą znamienną, że dążeniom do regionalnego definiowania procesów kulturowych towarzyszą tendencje do ujmowania modernizmu Europy Środkowo-Wschodniej jako kulturowo-historycznej i geopolitycznej całości odznaczającej się swoistymi rozwojowymi osobliwościami i własną wewnętrzną hierarchią problemową.

14 Podstawowe założenia literaturoznawczych badań archiwistycznych wyszczególnia D. Ulicka, 2010: Zwrot archiwalny (jak ja go widzę). „Teksty Drugie”, nr 1-2, s. 161.

15 B. Kalęba: Długa droga do litewskiego przekładu „Traktatu poetyckiego” Czesława MiŁosza - w niniejszym tomie.

16 Ibidem.

17 Zob. m.in. T. Brzostowska-Tereszkiewicz, 2016: Modernist Translation. An Eastern European Perspective. Models, Semantics, Functions. Frankfurt/M., Peter Lang.

18 E. Paczoska, 2017: Słowo wstępne..., s. 8. 
„Być może w najbliższych latach — prognozuje Mateusz Chmurski - możliwe będzie sformułowanie konkurencyjnego paradygmatu nowoczesności lokalnej, środkowoeuropejskiej”'19. Najnowsze propozycje typologicznego spojrzenia na bałkański modernizm ${ }^{20}$, słowiański modernizm ${ }^{21}$ lub modernizm wschodnioeuropejski podkreślają wprawdzie wspólnotę pytań $^{22}$ dotyczących procesów kształtowania się nowoczesności w regionie, ale jeszcze częściej akcentują różnorodność udzielanych odpowiedzi, wewnętrzną hybrydyczność i antynomiczność charakteryzowanych formacji artystyczno-światopoglądowych. Te ostatnie cechy wynikają z przeciwstawnych tendencji: gorliwych dążeń słowiańskich modernistów do możliwie pełnej, szybkiej i harmonijnej adaptacji zachodnioeuropejskich wzorców kulturowych do lokalnych tradycji i uwarunkowań oraz równie silnych ambicji ich twórczego przekształcenia i przezwyciężenia. Odrębność doświadczenia nowoczesności w badanych regionach wyjaśniana jest $\mathrm{z}$ jednej strony szczególnym splotem okoliczności historyczno-politycznych, kulturowych i społeczno-ekonomicznych (czas narodzin nacjonalizmów oraz powstawania utopii społecznych, politycznych, ideologicznych, naukowych i artystycznych przekraczających granice narodowych partykularyzmów ${ }^{23}$ ), a z drugiej - niezwykłą intensywnością twórczości przekładowej obarczanej tu szczególną kulturotwórczą odpowiedzialnością. Wśród najistotniejszych wyróżników modernistycznych kultur przekładowych należałoby przy tym wskazać osobliwe dowartościowanie nieprzekładalności, która w ujęciu Stanislava Vinavera, współredaktora serbskiej modernistycznej Biblioteki Albatros,

krystalizuje różnice kulturowe i umożliwia dialog między kulturą źródłową i docelową - dialog, który nie dąży do wymazywania lub niwelowania różnic, ale

19 M. Chmurski, 2013: Modernizm(y) Europy Środkowej. Rekonesans..., s. 16.

20 Zob. np. S. Bahun, 2012: The Balkans Uncovered: Toward Histoire Croisée of Modernism. W: M. Wollaeger, M. Eatough, eds.: Oxford Handbook of Global Modernisms. New York, Oxford University Press, s. 1-27.

21 G. Tichanov, 1996: Nietzsche and Early Slavic Modernism. W: E. Bojtar, ed.: The Comparable and the Incomparable: Comparative Studies in the Literatures of Central and Eastern Europe. Budapest, Central European University Comparative Literature Research Program, s. 67-103; S. Vladiv-Glover, 2002: Lyrical Drama, Slavic Modernism: Anton Chekhov, Milutin Bojić, Momčilo Nastasijević. „Southeastern Europe”. Zob. np. S. Roussenova, 2003: Slavic Modernism in Central and Eastern Europe. W: P. Poplawski, ed.: Encyclopedia of Literary Modernism. Westport, CT, Greenwood Press, s. 383-391.

22 By nawiązać do przywoływanego już wcześniej tytułu trzeciego tomu Problemów literatur i kultur modernizmu w Europie Środkowo-Wschodniej (1867-1918).

23 Zob. E. Paczoska, 2017: Stowo wstępne..., s. 11; E. Paczoska, J. Sadowski, eds., 2006: Homo utopicus, terra utopica. O utopii i jej lekturach. „Obóz. Problemy narodów byłego obozu komunistycznego", nr 45-46. 
przeciwnie, do wytwarzania nowości w interaktywnej komunikacji kultur, ich przenikania się lub wzajemnego odbijania się, z zachowaniem ich odrębności ${ }^{24}$.

To przekierowanie uwagi na różnice, które uchylają się przed przekładalnością, w żadnym wypadku nie oznacza kwestionowania konieczności przekładu czy obniżenia jego standardów. Wprost przeciwnie, jest wyrazem pogłębionej samoświadomości językowej, literackiej i kulturowej modernistycznych tłumaczy, a także podzielanego przez nich przekonania o twórczym potencjale nieporozumienia w kontaktach międzykulturowych ${ }^{25}$.

\section{Odrębna strefa przekładu}

Mimo istotnego znaczenia słowiańskich kultur przekładowych dla badań nad europejskimi modernizmami i modernistycznym przekładem literackim są one nadal, z różnych powodów historycznych i politycznych, niedostatecznie reprezentowane w dyskursie przekładoznawczym i komparatystycznym ${ }^{26}$. Tymczasem, jak przekonują historyczki ukraińskiego modernizmu, Tamara Hundorowa i Agnieszka Korniejenko, „słowiańskie modernizmy potraktowane bez kompleksu niższości i niepełnowartościowości mogą skutecznie zmienić poglądy europocentryczne"27 i otworzyć nowe przestrzenie badawcze. Temat prezentowanego tomu „Przekładów Literatur Słowiańskich” - Modernizm

24 Ž. Svirčev: Albatoss Translation Project - w niniejszym tomie (tłum. T.B.T.).

25 Szerzej na ten temat zob. T. Brzostowska-Tereszkiewicz, M. Rembowska-Płuciennik, B. Śniecikowska, eds., 2020: Understanding Misunderstanding. Vol. 1: Cross-Cultural Translation; vol. 2: Artistic Practices. Berlin, Peter Lang.

$26 \mathrm{~W}$ zachodnioeuropejskiej refleksji nad europejskimi modernizmami najczęściej eksponowany jest nadal rosyjski modernizm literacki i rosyjskie kultury przekładu. Zob. np. B.J. Baer, S. Witt, eds., 2018: Translation in Russian Contexts. Culture, Politics, Identity. London-New York, Routledge; A. Eysteinsson, V. Liska, eds., 2007: Modernism. Vol. 2. Amsterdam-Philadelphia, John Benjamins Publishing Company, s. 755-1007 (rozdział Locations: Case Studies). Choć można zaobserwować stopniowy wzrost zainteresowania zachodnio- i południowosłowiańskimi literaturami przekładowymi (m.in. B.J. Baer, ed., 2011: Contexts, Subtexts and Pretexts: Literary Translation in Eastern Europe and Russia. Amsterdam-Philadelphia, John Benjamins Publishing Company; „Przekłady Literatur Słowiańskich” 2016, t. 7, cz. 1-2: Tłumacze i przekładoznawstwo stowiańskie).

27 A. Korniejenko, 1998: Ukraiński modernizm. Próba periodyzacji procesu historycznoliterackiego. Kraków, Universitas, s. 97. Zob. też T. Hundorowa, 1998: Europejski modernizm czy europejskie modernizmy? ( perspektywy ukraińskiej). A. Korniejenko, tłum. W: R. Nycz, red.: Odkrywanie modernizmu. Kraków, Universitas, s. 521-529. 
w przekładzie - wynika z potrzeby zarówno zapewnienia i utrwalenia miejsca słowiańskich kultur przekładowych w dyskusji nad europejskim modernizmem literackim, jak i dokonania rewizji angloamerykańskich koncepcji modernistycznego przekładu literackiego ${ }^{28}$ z perspektywy słowiańskiego dyskursu przekładoznawczego i historycznoliterackiego.

Głównym zamierzeniem redaktorów i autorów było uchwycenie specyfiki modernistycznej kultury przekładowej w regionach, które Brian James Baer określił niegdyś mianem „wewnętrznego innego Europy” (Europe's internal other) ${ }^{29}$. Tę swoistość „alternatywnych [wobec zachodnioeuropejskich — T.B.T.] tradycji przekładowych" ${ }^{30}$ trafnie scharakteryzowała Yvonne Howell, podkreślając nie tylko ich ogromny rozwojowy dynamizm, silne upolitycznienie i w związku z tym dużą widoczność, lecz także niezwykle złożony i ambiwalentny charakter sztuki translatorskiej w mniej znanych regionach Europy, w których

przekład mógł uwidaczniać zarówno głębokie historyczne pęknięcia, jak i futurystyczne, transnarodowe marzenia. [...] [N]iejednokrotnie podkreślał obawy regionu dotyczące późnego startu w wyścigu do nowoczesności, ale służył także przypomnieniu siły utajonej w unikalnych zasobach duchowych i kulturowych regionu $^{31}$.

Artykuły zgromadzone w przedkładanym tomie pokazują, że rozpoznania brytyjskiej rusycystki, odnoszące się pierwotnie do wschodnioeuropejskiej literatury przekładowej, można wiązać także z południowo- i zachodniosłowiańskimi kulturami tłumaczenia. Wysoka dynamika przemian społeczno-politycznych, „późny start w wyścigu do nowoczesności”, a przede wszystkim konieczność „nadrabiania opóźnień” literatur słowiańskich w zakresie recepcji zachodniego modernizmu należą do istotnych zagadnień południowo- i zachodniosłowiańskiego dyskursu historyczno- i krytycznoprzekładowego; znajdują też odzwierciedlenie w prezentowanych tu tekstach. Podejmując Problem sceniczności w polskim przekładzie „Trylogii dubrownickiej” Iva Vojnovicia, Magdalena Ślawska przypomina, że „[m]odernizm chorwacki, który jak pozostałe modernizmy słowiańskie narodził się w atmosferze politycznego rozpadu”, cechuje „otwarcie

28 Przede wszystkim sformułowanych przez takich badaczy, jak S.G. Yao, 2002: Translation and the Languages of Modernism. Gender, Politics, Language. New York, Palgrave Macmillan i L. Venuti, 2002: Margin. W: Idem: The Translator's Invisibility. A History of Translation. 2nd ed. London-New York, Routledge, s. 164-236.

29 B.J. Baer, 2011: Introduction. Cultures of Translation. W: Contexts, Subtexts and Pretexts..., s. 1 (kursywa w oryginale).

30 B.J. Baer, 2011: Introduction. Cultures of Translation..., s. 1.

31 Y. Howell, 2019: Through a Prism, Translated: Culture and Change in Russia. W: M. Reynolds, ed.: Prismatic Translation. Cambridge, Legenda, s. 128 (tłum. T.B.T.). 
na Zachód” służące poszukiwaniu wzorców literackich, „zbliżeniu do »centrum nowoczesności« i wyrównaniu poziomu artystycznego" ${ }^{32}$. Szczególne uprzywilejowanie i swoiste kierunki ewolucji naturalizmu jako łącznika między dawną a nową epoką w chorwackim dramacie modernistycznym badaczka tłumaczy istotnym zapóźnieniem tego regionu kulturowego wobec tendencji, które już od dawna oddziaływały na procesy historycznoliterackie w Europie Zachodniej. Autorka odwołuje się do rozpoznań serbisty i kroatysty, a zarazem poety-tłumacza Juliana Kornhausera, który podkreśla kolejną istotną cechę słowiańskiej kultury przekładowej, będącą pochodną dążeń do realizacji przyspieszonego kursu modernizmu: swoistą transkulturową palimpsestowość, wzajemne nawarstwianie się obcych i rodzimych tendencji ideowo-artystycznych: „Wszak do tej pory literatury mniejszych narodów słowiańskich odczuwały kompleks niższości, wynikający z wyraźnego zapóźnienia procesów historycznoliterackich, co prowadziło do nakładania się prądów w celu nadrabiania zaległości” ${ }^{33}$. Ten stylistyczny pluralizm ${ }^{34}$, związany $\mathrm{z}$ jednej strony $\mathrm{z}$ asymetrią rozwoju kulturowo-politycznego regionów, a z drugiej - z postępującymi procesami modernistycznej globalizacji i hybrydyzacji literatury, należy do najważniejszych wyróżników nowoczesnego przekładu literackiego w Europie Środkowo-Wschodniej. Złożona problematyka artystycznych kryteriów definiowania przekładu modernistycznego wymaga jednak podjęcia odrębnych badań z zakresu poetyki historycznej przekładu w poszczególnych europejskich literaturach narodowych. Być może warto byłoby zaryzykować opis przekładu modernistycznego w kulturach słowiańskich w kategoriach formacji stylistycznej definiowanej przez Aleksandara Flakera jako swoista, historycznie wytworzona, ponadnarodowa, względnie jednorodna całość ${ }^{35}$.

Podejmując problem nadrabiania kulturowych zaległości, Andrij Saveneć omawia rosyjskie i ukraińskie tłumaczenia powieści Davida Herberta Lawrence’a Lady Chatterley's Lover (1928) jako znacznie spóźnione, ale za to właśnie dlatego najbardziej zauważalne ${ }^{36}$ próby przyswojenia dziedzictwa anglojęzycznego modernizmu przez literaturę ukraińską i rosyjską u schyłku ZSRR. Istotnie, jak przekonuje Baer, „przeświadczenie, że narody Europy Wschodniej

32 M. Ślawska: Problem sceniczności w polskim przekładzie „Trylogii dubrownickiej” Iva Vojnovicia - w niniejszym tomie.

33 J. Kornhauser, 1994: Literatury zachodnio- i południowosłowiańskie XX wieku w ujęciu porównawczym. Kraków, Wydawnictwo Uniwersytetu Jagiellońskiego, s. 9.

34 Zob. I. Medić: Wilde about Wilde - The Translation of Oscar Wilde’s "Salomé" in Croatian Literature of the Early 20th Century - w niniejszym tomie.

35 Zob. A. Flaker, 1976: Stilske formacije. Zagreb, Liber.

36 Zob. A. Saveneć: Modernistyczna obsceniczność w przekładzie: ukraińskie i rosyjskie tlumaczenia „Kochanka Lady Chatterley” D.H. Lawrence'a u schytku ZSRR - w niniejszym tomie. 
muszą »dogonić« bardziej rozwinięty Zachód i zrekompensować spóźnione wejście w nowoczesność, sprawiło, że tłumaczenie stało się tam bardzo widoczną, często samoświadomą i szeroko dyskutowaną praktyką"”37. Przekład był postrzegany zarówno jako „wstydliwe przypomnienie opóźnień kulturowych”,38, jak i nader skuteczny sposób ich przezwyciężenia oraz poligon doświadczeń artystycznych. Amerykański przekładoznawca podkreśla, że to właśnie zaangażowanie na rzecz misji kulturowej pomaga wyjaśnić bardzo wysoki społeczny status sztuki przekładowej w kulturach słowiańskich - uprawianej tam, jak pisze Baer, z wyjątkową powagą i wytrwałością ${ }^{39}$. Wypada jednak podkreślić, że rozpoznania Yvonne Howell i Briana Jamesa Baera, choć wynikające z tendencji lokalizacyjnych, wyczulone na specyfikę środkowo- i wschodnioeuropejskich kultur tłumaczeniowych, mogą prowadzić do nadmiernego upraszczania słowiańskich modeli przekładu literackiego w odniesieniu do specyficznych dla regionu uwarunkowań kulturowo-politycznych traktowanych jako czynnik silnie ujednolicający. Najważniejszym zadaniem badaczy słowiańskich modernizmów jest eksponowanie tego, co różnicuje sposoby teoretyzacji i praktyczne zastosowania nowoczesności w przekładzie literackim w poszczególnych kulturach środkowo- i wschodnioeuropejskich. Dynamikę międzyjęzykowego i międzykulturowego dialogu modernistycznego najpełniej odsłaniają analizy porównawcze tekstów źródłowych i docelowych na gruncie poetyki historycznej przekładu, w odniesieniu do różnorodnych trendów słowiańskiej refleksji przekładoznawczej.

\section{Albatrosy modernizmu: przekłady w literaturach słowiańskich}

Tom, który oddajemy do rąk Czytelników, zawiera artykuły przekładoznawców i literaturoznawców-komparatystów zainteresowanych problematyką przekładu modernistycznego w literaturach słowiańskich rozumianych jako „odrębna strefa przekładu, odmienna od innych" ${ }^{40}$. Historyczny materiał porównawczy stanowią zarówno przekłady poetyckie, prozatorskie, dramatyczne, jak i filozoficzne, powstałe na gruncie modernizmów: polskiego, rosyjskiego, ukraińskiego,

37 B.J. Baer, 2011: Introduction. Cultures of Translation..., s. 4.

38 Ibidem.

39 Ibidem, s. 5.

40 Y. Howell, 2019: Through a Prism, Translated..., s. 128. 
czeskiego, chorwackiego, serbskiego, słoweńskiego i litewskiego. Zamykający tom wywiad Sylwii Siedleckiej z Wojciechem Gałązką dodatkowo poszerza te konteksty o literaturę bułgarską. Znamienne, że studia nad modernistycznym przekładem literackim zgromadzone w niniejszym tomie są raczej wynikiem historyzującego, archiwistycznego zaangażowania badawczego niż namysłu teoretycznego nad wyznacznikami nowoczesności w tłumaczeniu literackim czy refleksji metodologicznej nad sposobami uprawiania historii modernistycznego przekładu. Skupiają się przeważnie na studiach przypadków, prezentacji wybranych fragmentów dziejów literatury narodowej (np. wczesnomodernistycznej literatury ukraińskiej) lub historii recepcji poszczególnych utworów, odraczając uogólniającą refleksję na temat specyfiki modernistycznego przekładu literackiego w Europie Środkowo-Wschodniej i znaczenia twórczości translatorskiej w kulturach słowiańskich. Zestawione obok siebie uwidaczniają jednak podobne tendencje badawcze, przede wszystkim nachylenie w kierunku przekładocentrycznej komparatystyki literackiej, dążenie do rewizji historii regionalnych modernizmów literackich i rozciągania chronologicznych granic modernizmu, a także zbliżone poglądy na rolę przekładu artystycznego w rozwoju nowoczesnych literatur słowiańskich.

Autorzy zgodnie podkreślają fundamentalne znaczenie przekładu jako „artefaktu kulturowego i literackiego" ${ }^{41} \mathrm{w}$ rozwoju regionalnych odmian europejskiego modernizmu. Silne ukierunkowanie słowiańskich modernizmów na przekład zyskuje potwierdzenie w analizach czeskich tłumaczeń liryki słoweńskiego poety romantycznego Francego Prešerna (artykuł Alenki Jensterle-Doležal), włoskich i chorwackich tłumaczeń poezji słoweńskiego konstruktywisty Srečka Kosovela (tekst Roberta Grošelja) lub serbskich tłumaczeń amerykańskich modernistów (artykuł Bojany Aćamović). Stymulacyjną, dopełniającą i zarazem autorewizyjną rolę tłumaczeń w historii literatur słowiańskich dobitnie ukazuje dwugłos Žarki Svirčev i Bojany Aćamović o „Bibliotece Albatros” - serbskim projekcie przekładowym hołdującym ideom modernistycznego ,intuicjonizmu, dynamizmu, chaosu, kosmizmu i ekspresjonizmu"42. Jak pisze serbska literaturoznawczyni: „Przekład jest ważnym czynnikiem nie tylko poszerzania repertuaru literackiego i transferu idei estetycznych, ale także otwierania na nowe możliwości rozumienia i repozycjonowania własnej kultury" ${ }^{\text {"43 }}$, co oznacza między innymi samodzielne przewartościowywanie opozycji centrum i peryferii, a także ustalanie kanonów literatury światowej.

41 Przywołuję tu tytuł artykułu Alenki Jensterle-Doležal Prevod kot kulturni in literarni artefakt. Premerjava dveh čeških prevodov Prešernove pesmi "Slovo od mladosti” w niniejszym tomie.

42 Ž. Svirčev: Albatoss Translation Project - w niniejszym tomie.

43 Ibidem.

\begin{tabular}{l|l} 
PLS.2021.11.01.17 | & s. $11 \mathrm{z} 18$
\end{tabular} 
Zaproszeni do tomu przekładoznawcy-komparatyści wskazują na konieczność rewizji wielu ustaleń zachodnioeuropejskich badań nad modernizmem, przede wszystkim przeświadczeń o antytradycjonalizmie awangardy, modernistycznej dominacji elitarnego modelu literatury czy niechęci modernistów do literatury popularnej - z perspektywy literatur Europy Środkowo-Wschodniej. Szczególną uwagę przykuwają zagadnienia nieznajomości języka oryginału jako wyróżnika, a nawet swoistej normy modernistycznego przekładu literackiego ${ }^{44}$, a także ważnego źródła nowoczesnej kreatywności i innowacyjności. Barbara Bibik uświadamia kluczową rolę niemieckiej wersji językowej Orestei Ajschylosa w przekładzie Jana Kasprowicza (Potrzeba tłumacza). Z kolei Igor Medić pokazuje, że pośrednictwo innojęzycznego przekładu (niemieckiego tłumaczenia Salomé Oskara Wilde’a) stymuluje uniezwyklającą egzotyzację chorwackiego tekstu docelowego: „odnajdując odpowiedniki [niemieckich — T.B.T.] idiomów w rodzimym bogactwie kodów językowych, przekład chorwacki osiąga doceniane bogactwo leksykalne i złożoność wersji niemieckiej. Całość przyjmuje formę »językowego kolażu «"45. Trzeba podkreślić, że problemy wykorzystania twórczego potencjału nierozumienia języków obcych, żywiołu wielojęzyczności i rezygnacji z przekładu w utworach artystycznych należą do najintensywniej eksplorowanych obszarów badawczych w najnowszych zachodnioeuropejskich badaniach nad modernizmem ${ }^{46}$. Podobnie - w samym centrum współczesnych studiów porównawczych nad modernizmem - sytuują się rozważania nad specyfiką modernistycznych przekładów literatury antycznej ${ }^{47}$. Tropiąc idiolekt poetycki Kasprowicza w jego przekładach Orestei Ajschylosa i pierwiastki ajschylejskie w oryginalnej twórczości młodopolskiego poety, Barbara Bibik zwraca uwagę na organiczny związek wczesnomodernistycznej twórczości oryginalnej i przekładowej. W odniesieniu do tego samego okresu literatury

44 O modernistycznym rozpowszechnieniu przekonania, że znajomość języka oryginału nie jest niezbędna do podjęcia pracy translatorskiej pisał S.G. Yao, 2002: Translation and the Languages of Modernism..., s. 18, 26. Historia refleksji translatorskiej i literatury przekładowej wcześniejszych epok dostarcza oczywiście licznych precedensów odchodzenia od zasady znajomości języka oryginału jako koniecznego warunku tłumaczenia.

45 I. Medić: Wilde about Wilde - The Translation of Oscar Wilde's "Salomé" in Croatian Literature of the Early 20th Century - w niniejszym tomie (tłum. T.B.T.).

46 Zob. np. J. Taylor-Batty, 2020: On Not Knowing Languages: Modernism, Untranslatability and Newness. W: T. Brzostowska-Tereszkiewicz, M. Rembowska-Płuciennik, B. Śniecikowska, eds.: Understanding Misunderstanding. Vol. 1..., s. 41-65; J. Harding, J. Nash, eds., 2019: Modernism and Non-Translation. Oxford, Oxford University Press.

47 Najnowsze trendy badań nad "klasycznymi modernizmami” ukazuje m.in. monografia M. Hickman, L. Kozak, eds., 2019: The Classics in Modernist Translation. London, Bloomsbury Academic. 
polskiej problemy poetyki procesu tłumaczenia i autorskiej poetyki tłumacza podejmuje Katarzyna Lukas w artykule „Tako rzecze Zaratustra” Wacława Berenta: młodopolska maniera czy nowatorski eksperyment?. Przekładoznawczyni wyodrębnia trzy zachodzące na siebie kody językowo-literackie prozy poetyckiej Fryderyka Nietzschego w polskiej wersji językowej: poetycki idiolekt Berenta, styl poetycki Młodej Polski oraz język biblijny jako wzorzec archaizacyjny. Uwypuklając jednocześnie silne inspiracje nietzscheańskie w pisarstwie polskiego prozaika, pokazuje Tako rzecze Zaratustra jako „»quasi-oryginał«, naznaczony niepowtarzalną sygnaturą polskiego pisarza" ${ }^{48}$ i proponuje ujęcie twórczości oryginalnej i przekładowej polskiego modernisty jako kontinuum. W prezentowanych tekstach przekład ujmowany jest jednak nie tylko jako modus twórczej aktywności, manifestacja modernistycznej wrażliwości artystycznej i samoświadomości kulturowej, lecz także jako medium rozprzestrzeniania się nowoczesnych idei antropologicznych i społecznych. Artykuły Andrija Sawenecia (Modernistyczna obsceniczność w przekładzie: ukraińskie i rosyjskie tłumaczenia "Kochanka Lady Chatterley” D.H. Lawrence’a u schyłku ZSRR) i Tei Rogić Musy (Modernizm międzywojenny: Nałkowska i Krleža - metafora "niedobrej miłości” w literaturach polskiej i chorwackiej) uwidaczniają sposoby przełamywania tabu obyczajowego i językowego, wskazując na estetyczne dowartościowanie szoku w modernistycznych praktykach artystycznych.

Przekład ujmowany jest jako integralna część modernistycznego programu odnowy literatury i narzędzie transmisji nowoczesnego imperatywu inwencyjności (w rozważaniach Bojany Aćamović o roli przekładów Edgara Allana Poego i Walta Whitmana w ewolucji serbskiej awangardy lub artykule Alenki Jensterle-Doležal o eksperymentalnym podejściu czeskich tłumaczy do poezji Francego Prešerna i wyostrzonej samoświadomości językowej jako wyróżniku modernistycznego przekładu). Twórczość translatorska to także silny stymulator ewolucji „mniejszych literatur” i skuteczne „narzędzie planowania kulturowego w kulturach o małym wpływie" ${ }^{49}$ (np. w artykule Žarki Svirčev Albatross Translation Project).

Rozważany w kolejnych artykułach przekład modernistyczny nie jest tożsamy ani z określonym zbiorem kanonicznych tekstów, ani z konkretnym typem doświadczeń translatorskich. Stanowi raczej zestaw pytań i problemów wyłaniających się w różnojęzycznych badaniach porównawczych nad regionalnymi modernizmami literackimi. Rozważania o tłumaczeniach w literaturach słowiańskich potwierdzają, że paradygmat translatorskiej nowoczesności

$48 \mathrm{~W}$ niniejszym tomie.

49 By przywołać rozważania M. Ožbot, 2021: Translation and Multilingualism. A Dynamic Interaction. Ljubljana, Oddelek za romanske jezike in književnosti, s. 7-16. 
obejmuje zjawiska nie tylko różnorodne i odmienne, ale nawet zasadniczo przeciwstawne i wykluczające $\operatorname{się}^{50}$, jak tradycjonalizm w słowackiej praktyce przekładowej w dobie tzw. normalizacji po 1968 roku (omawiany w tekście Lucyny Spyrki) i przekładowy eksperymentalizm z okresu drugiej fali czeskiej awangardy (analizowany w artykule Alenki Jensterle-Doležal), wysoki, ocalający humanizm poetyckich tłumaczeń Tomasa Venclovy (podkreślany przez Beatę Kalębę) i subwersyjne praktyki przekraczania tabu językowego i obyczajowego w przekładzie (tekst Andrija Sawenecia).

Tom, który oddajemy do rąk Czytelników, jest zapowiedzią międzynarodowej konferencji przekładoznawczej Modernism in Translation / Modernizm w przekładzie, która została przesunięta na późniejszy termin z powodu pandemii COVID-19. Składając podziękowania Autorom za wysiłek włożony w pracę nad tekstami w warunkach lockdownu i komunikacji zdalnej, serdecznie zapraszamy do kontynuowania dyskusji na temat różnych sposobów praktykowania i teoretyzowania „nowoczesności w przekładzie” w kulturach słowiańskich. Ponieważ liczba zgłoszonych tekstów przewyższyła możliwości wydawnicze, do problematyki modernistycznych przekładów literackich powrócimy w kolejnym tomie „Przekładów Literatur Słowiańskich”.

\section{Literatura}

Bahun S., 2012: The Balkans Uncovered: Toward Histoire Croisée of Modernism.

W: M. Wollaeger, M. Eatough, eds.: Oxford Handbook of Global Modernisms.

New York, Oxford University Press, s. 1-27.

Baer B.J., 2011: Introduction. Cultures of Translation. W: B.J. Baer, ed.: Contexts,

Subtexts and Pretexts: Literary Translation in Eastern Europe and Russia. Amsterdam-Philadelphia, PA, John Benjamins Publishing, s. 1-15.

Baer B.J., Witt S., eds., 2018: Translation in Russian Contexts. Culture, Politics, Identity. London-New York, Routledge.

Bolecki W., 2012: Modalności modernizmu. Studia - analizy - interpretacje. Warszawa, Wydawnictwo IBL PAN.

Brooker P., Thacker A., eds., 2005: Geographies of Modernism: Literatures, Cultures, Spaces. London-New York, Routledge.

50 Szerzej na temat antynomiczości modernizmu i modernistycznego przekładu literackiego zob. W. Bolecki, 2012: Modalności modernizmu. Studia - analizy - interpretacje. Warszawa, Wydawnictwo IBL PAN, s. 8; T. Brzostowska-Tereszkiewicz, 2015: Przekład modernistyczny (modele i opozycje). W: W. Bolecki, W. Soliński, M. Gorczyński, red.: Współczesne dyskursy konfliktu: literatura - kultura - język. Warszawa, Wydawnictwo IBL PAN, s. 45-90. 
Brzostowska-Tereszkiewicz T., 2015: Przekład modernistyczny (modele i opozycje). W: W. Bolecki, W. Soliński, M. Gorczyński, red.: Współczesne dyskursy konfliktu: literatura - kultura - język. Warszawa, Wydawnictwo IBL PAN, s. $45-90$.

Brzostowska-Tereszkiewicz T., 2016: Modernist Translation. An Eastern European Perspective. Models, Semantics, Functions. Frankfurt/M., Peter Lang.

Brzostowska-Tereszkiewicz T., 2016: The Translational Turn in Modernism Studies. W: A. Adamowicz-Pośpiech, M. Mamet-Michalkiewicz, eds.: Translation in Culture. Katowice, Wydawnictwo Uniwersytetu Śląskiego, s. 13-38.

Brzostowska-Tereszkiewicz T., Rembowska-Płuciennik M., Śniecikowska B., eds., 2020: Understanding Misunderstanding. Vol. 1: Cross-Cultural Translation. Berlin, Peter Lang.

Brzostowska-Tereszkiewicz T., Rembowska-Płuciennik M., Śniecikowska B., eds., 2020: Understanding Misunderstanding. Vol. 2: Artistic Practices. Berlin, Peter Lang.

Chesterman A., 2009: The Name and Nature of Translator Studies. „Hermes”, nr 42 , s. $13-22$.

Chmurski M., 2013: Modernizm(y) Europy Środkowej. Rekonesans. „Przegląd Filozoficzno-Literacki", nr 1-2, s. 1-17.

Doyle L., Winkiel L., 2005: Introduction: The Global Horizons of Modernism. W: L. Doyle, L. Winkiel, eds.: Geomodernism. Race, Modernism, Modernity. Bloomington, Indiana University Press, s. 1-14.

Eysteinsson A., Liska V., eds., 2007: Modernism. Vol. 2. Amsterdam-Philadelphia, John Benjamins Publishing Company.

Flaker A., 1976: Stilske formacije. Zagreb, Liber.

Fordham F., 2010: The Modernist Archive. W: P. Brooker et al., eds.: The Oxford Handbook of Modernisms. Oxford, Oxford University Press, s. 45-60.

Friedman S.S., 2007: Cultural Parataxis and Transnational Landscapes of Reading. Toward a Locational Modernist Studies. W: A. Eysteinsson, V. Liska, eds.: Modernism. Vol. 1. Amsterdam-Philadelphia, Johns Benjamins Publishing, s. $35-52$.

Feldman M., Tonning E., Svendsen A., eds., 2021: Historicizing Modernists. Approaches to "Archivalism”. London, Bloomsbury Academic.

Harding J., Nash J., eds., 2019: Modernism and Non-Translation. Oxford, Oxford University Press.

Hickman M., 2019: Introduction. W: M. Hickman, L. Kozak, eds.: The Classics in Modernist Translation. London, Bloomsbury Academic, s. 1-18.

Howell Y., 2019: Through a Prism, Translated: Culture and Change in Russia. W: M. Reynolds, ed.: Prismatic Translation. Cambridge, Legenda, s. $121-139$. 
Hundorowa T., 1998: Europejski modernizm czy europejskie modernizmy? (z perspektywy ukraińskiej). A. Korniejenko, tłum. W: R. Nycz, red.: Odkrywanie modernizmu. Kraków, Universitas, s. 521-529.

Kalęba B., 2019: Wyrwa w świecie. Przekład literacki w sowieckiej Litwie - casus Tomasa Venclovy i rówieśników. Kraków, Wydawnictwo Uniwersytetu Jagiellońskiego.

Kita-Huber J., Makarska R., red., 2020: Wyjść tłumaczowi naprzeciw. Miejsce tłumacza w najnowszych badaniach translatologicznych. Kraków, Universitas.

Knapp J., 2003: „Ocular Proof”: Archival Revelations and Aesthetic Response. „Poetics Today”, nr 4, s. 695-727.

Kornhauser J., 1994: Literatury zachodnio- i południowosłowiańskie XX wieku w ujęciu porównawczym. Kraków, Wydawnictwo Uniwersytetu Jagiellońskiego.

Korniejenko A., 1998: Ukraiński modernizm. Próba periodyzacji procesu historycznoliterackiego. Kraków, Universitas.

Latham S., Rogers G., red., 2021: The New Modernist Studies Reader: An Anthology of Essential Criticism. [S.1.], Bloomsbury Publishing.

Mao D., Walkowitz R.L., 2014: Nowe studia modernistyczne. A. i M. Kęsiakowie, tłum. „Poznańskie Studia Polonistyczne. Seria Literacka”, nr 24, s. 97115.

Milthorpe N., 2019: Archives, Authority, Aura: Modernism's Archival Turn. „Papers on Language and Literature", nr 1, s. 3-15.

Ožbot M., 2021: Translation and Multilingualism. A Dynamic Interaction. Ljubljana, Oddelek za romanske jezike in književnosti.

Paczoska E., 2017: Słowo wstępne. W: E. Paczoska, I. Poniatowska, M. Chmurski, red.: Problemy literatury i kultury modernizmu $w$ Europie Środkowo-Wschodniej (1867-1918). T. 1: Teksty doświadczenia. Warszawa, Wydawnictwa Uniwersytetu Warszawskiego, s. 7-15.

Paczoska E., Poniatowska I., Chmurski M., red., 2017: Problemy literatury i kultury modernizmu w Europie Środkowo-Wschodniej (1867-1918). T. 1: Teksty doświadczenia. Warszawa, Wydawnictwa Uniwersytetu Warszawskiego.

Paczoska E., Poniatowska I., Chmurski M., red., 2017: Problemy literatury i kultury modernizmu w Europie Środkowo-Wschodniej (1867-1918). T. 2: Doświadczenia tekstu. Warszawa, Wydawnictwa Uniwersytetu Warszawskiego.

Paczoska E., Poniatowska I., Chmurski M., red., 2017: Problemy literatury i kultury modernizmu w Europie Środkowo-Wschodniej (1867-1918). T. 3: Wspólnota pytań. Antologia. Warszawa, Wydawnictwa Uniwersytetu Warszawskiego. Paczoska E., Sadowski J., red., 2006: Homo utopicus, terra utopica. O utopii i jej lekturach. „Obóz. Problemy narodów byłego obozu komunistycznego”, nr 45-46. 
Poniatowska I., 2017: Słowo wstępne. W: E. Paczoska, I. Poniatowska, M. Chmurski, red.: Problemy literatury $i$ kultury modernizmu $w$ Europie Środkowo-Wschodniej (1867-1918). T. 3: Wspólnota pytań. Antologia. Warszawa, Wydawnictwa Uniwersytetu Warszawskiego, s. 7-11.

„Porównania” 2020, nr 1: Czynnik ludzki w przekładzie literackim. Teorie, historie, praktyki.

„Przekłady Literatur Słowiańskich” 2016, t. 7, cz. 1-2: Tłumacze i przekładoznawstwo słowiańskie.

Pym A., 2009: Humanizing Translation History. „Hermes”, nr 22, s. 23-48.

Roussenova S., 2003: Slavic Modernism in Central and Eastern Europe. W: P. Poplawski, ed.: Encyclopedia of Literary Modernism. Westport, CT, Greenwood Press, s. 383-391.

Taylor-Batty J., 2020: On Not Knowing Languages: Modernism, Untranslatability and Newness. W: T. Brzostowska-Tereszkiewicz, M. Rembowska-Płuciennik, B. Śniecikowska, eds.: Understanding Misunderstanding. Vol. 1: Cross-Cultural Translation. Berlin, Peter Lang, s. 41-65.

Tichanov G., 1996: Nietzsche and Early Slavic Modernism. W: E. Bojtar, ed.: The Comparable and the Incomparable: Comparative Studies in the Literatures of Central and Eastern Europe. Budapest, Central European University Comparative Literature Research Program, s. 67-103.

Tyšš I., Gromová E., 2020: Taking Matters into our Own Hands: Humanizing Slovak Translation History. „Porównania”, nr 1, s. 157-176.

Ulicka D., 2010: Zwrot archiwalny (jak ja go widze). „Teksty Drugie”, nr 1-2, s. $159-164$.

Venuti L., 2002: The Translator's Invisibility. A History of Translation. 2nd ed. London-New York, Routledge.

Vladiv-Glover S., 2002: Lyrical Drama, Slavic Modernism: Anton Chekhov, Milutin Bojić, Momčilo Nastasijević. „Southeastern Europe”, vol. 18.

Yao S.G., 2002: Translation and the Languages of Modernism. Gender, Politics, Language. New York, Palgrave Macmillan.

Yao S.G., 2013: Translation Studies and Modernism. W: J.-M. Rabaté, ed.: A Handbook of Modernism Studies. West Sussex, Wiley-Blackwell, s. 209-223.

Yao S.G., 2019: Foreword. The Classics, Modernism and Translation: A Conflicted History. W: M. Hickman, L. Kozak, eds.: The Classics in Modernist Translation. London, Bloomsbury Academic, s. xv-xvi. 


\section{Tamara Brzostowska-Tereszkiewicz \\ Przekład modernistyczny w kulturach słowiańskich Kilka uwag wstępnych}

STRESZCZENIE | Celem artykułu jest zwięzłe przedstawienie kondycji badań nad modernizmami literackimi Europy Środkowo-Wschodniej w kontekście zwrotu transnarodowego, zwrotu translacyjnego i zwrotu archiwalnego w nowych badaniach modernistycznych. Rozważania na temat specyfiki słowiańskich kultur przekładu artystycznego oraz możliwości reorientacji i zrównoważenia zachodnioeuropejskich badań nad literackim modernizmem inspirowane są nowymi badaniami nad transnarodowymi powiązaniami między słowiańskimi modernizmami, które są prezentowane w niniejszym tomie.

SŁOWA KLUCZOWE | słowiański modernizm, badania porównawcze nad modernizmem, zwrot transnarodowy, przekład modernistyczny

\section{Тамара Бжостовска-Тэрэшкевич}

\section{Модернистский перевод в славянских культурах Несколько предварительных замечаний}

РЕЗЮМЕ | Целью статьи является краткое представление состояния исследований в области литературного модернизма в Центральной и Восточной Европе в контексте транснационального поворота, трансляционного поворота и архивального поворота в новых исследованиях модернизма. Размышления о специфике славянских культур художественного перевода и их способности перенаправить и сбалансировать западноевропейские исследования литературного модернизма вдохновлены новыми исследованиями транснациональных связей между славянскими модернизмами, представленными в этом сборнике.

КЛЮЧЕВЫЕ СЛОВА | славянский модернизм, сравнительные исследования модернизма, транснациональный поворот, модернистский перевод

TAMARA BRZOSTOWSKA-TERESZKIEWICZ | dr hab., prof. w Instytucie Badań Literackich PAN; polonistka i anglistka, literaturoznawczyni, przekładoznawczyni, tłumaczka. Autorka monografii Ewolucje teorii. Biologizm w modernistycznym literaturoznawstwie rosyjskim (2011) i Modernist Translation. An Eastern European Perspective. Models, Semantics, Functions (2016) oraz artykułów z historii literaturoznawstwa wschodnio- i środkowoeuropejskiego, historii myśli przekładoznawczej, komparatystyki literackiej oraz teorii przekładu artystycznego. 